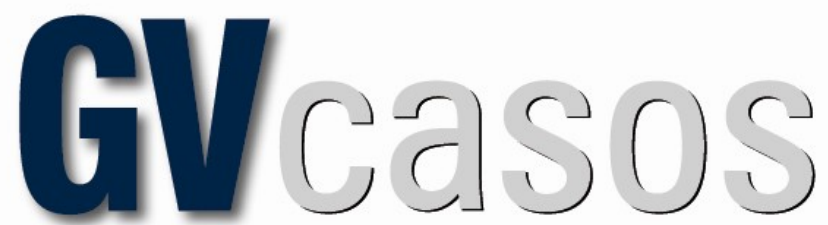

Volume 9

Número 1

Jan/Jun 2019

Doc. 2

Rev. Bras. de Casos de Ensino em Administração

ISSN 2179-135X

DOI: http://dx.doi.org/10.12660/gvcasosv9n1c2

\title{
JOHNNIE WALKER: SEMPRE EM FRENTE Johnnie Walker: always forward
}

LeVy HenRIQue Barbosa dos SANTos - levyhenrique@hotmail.com

Centro Universitário Maurício de Nassau - Aracaju, SE, Brasil

BEATRIZ Gondim MATOS - gm.beatriz@gmail.com

Universidade Federal do Cariri - Juazeiro do Norte, CE, Brasil

Submissão: 02/01/2019 | Aprovação: 20/05/2019

\begin{abstract}
Resumo
A marca Johnnie Walker enfrentou dificuldades ao longo de 150 anos de existência. A partir da década de 1990, uma inesperada perda de market share afetou a história de ascensão da marca. O segmento de uísque foi perdendo espaço para outras bebidas, como vinho, champanhe, vodca e bebidas prontas, como a Smirnoff Ice. Os jovens enxergavam o uísque como "a bebida de seus pais". A ideia de que beber uísque trazia status tinha envelhecido junto com a história. O caso se propõe a apresentar as estratégias de revitalização da marca adotadas pela organização.
\end{abstract}

Palavras-chave: gestão de marca, branding, identidade de marca, internacionalização de marca.

\begin{abstract}
The Johnnie Walker brand has faced difficulties over all its 150 years of existence. From the 1990s, they have occurred when an unexpected loss of market share affected the brand's rise history. The whiskey segment was loosing place for other beverages, such as wine, champagne, vodka, and others like Smirnoff Ice. The young public regardedwhiskey as the drink "of their parents". The idea of drinking whiskey as a source of status had aged along with history. The case aims to present the brand revitalization strategies adopted by the organization to reverse the frame.

Keywords: brand management, branding, brand identity, brand internationalization.
\end{abstract}

\section{A história}

A Johnnie Walker tem uma história que se estende por três gerações de uma família. John, mais conhecido como Johnnie, era filho do fazendeiro Alexander Walker, que morreu em 1819, e o rapaz, então com 14 anos, era considerado muito novo para continuar tocando a fazenda da família. Com a venda da fazenda, John abriu uma pequena mercearia em 1820, na cidade de Kilmarnock, localizada no oeste da Escócia. O pequeno estabelecimento comercializava chás, vinhos, bebidas e comidas secas, começando a desenvolver uma clientela de boa reputação. Enquanto isso, o mercado de uísque estava mudando no mundo inteiro. As destilarias, muitas delas ilícitas, começaram a se profissionalizar, e ele enxergou uma oportunidade de ingressar nesse ramo de atividade. "Se eu posso misturar diferentes tipos de chá, por que não posso fazer o mesmo com diferentes maltes de uísque? ", teria dito John, num primeiro impulso de inovação, começando a destilar seu próprio uísque já em 1825, como uma maneira de oferecer um produto único e consistente.

Utilizando sua habilidade, iniciou a produção do uísque. Os clientes logo começaram a exigir um nome para a bebida. Foi em 1850 que o uísque ganhou o nome de Walker's Old Highland. Em 1857, o filho de John, Alexander, assumiu os negócios da família, com a morte de seu pai, e continuou desenvolvendo e expandindo a empresa. Pouco depois, em 1860, ele criou a tradicional 
garrafa quadrada. Num segmento que utilizava principalmente garrafas redondas, rapidamente o uísque se tornou mundialmente reconhecido. "As embalagens desse tipo quebram mais dificilmente que as redondas, o que facilitava a logística na hora de exportar o produto para fora da Escócia", explica Eliza Duque Estrada, brand manager da marca. Pouco depois, em 1867, Alexander resolveu colar o tradicional rótulo na diagonal, por conta de o nome Walker's Old Highland ser muito extenso. "Hoje, o rótulo na diagonal e a garrafa quadrada são valiosos ativos da identidade da marca", diz Charles Allen, diretor mundial de brand da atual fabricante Diageo. Finalmente, em 1876, ele conseguiu registrar como marca o modelo da tradicional garrafa quadrada e as cores, preto e ouro, das escritas de seu rótulo. No ano seguinte, foi a vez de registrar o tradicional rótulo inclinado. Em 1879, a destilaria ganhou sua primeira medalha por seus uísques, numa competição internacional realizada em Sydney. Logo esses uísques ganhariam medalhas em Melbourne, Adelaide e Paris. Em 1880, a empresa abriu escritório na cidade de Londres, por onde exportava seus produtos para o resto do mundo.

Quando Alexander morreu, em 1889, deixou o negócio para seus dois filhos, George e Alexander II. Alexander II ficou responsável pela produção dos uísques e George viajava o mundo estabelecendo uma rede de distribuição. Em 1893, eles compraram a tradicional destilaria Cardhu, garantindo assim o suprimento de maltes excepcionais e mantendo-os longe de seus principais concorrentes. Em 1906, os irmãos Walker já possuíam três uísques no mercado (Anexo 1), cada um deles identificado por distintos rótulos coloridos: Old Highland Whisky (envelhecido 5 anos e identificado pelo rótulo branco), Special Old Highland (envelhecido 8 anos e identificado pelo rótulo vermelho) e o Extra Special Old Highland (envelhecido 12 anos e identificado pelo rótulo preto). $\mathrm{O}$ do rótulo branco era um uísque mais jovem, mais barato e de qualidade inferior aos outros. Temendo que um produto de baixa qualidade fosse nocivo à marca, eles o descontinuaram.

Finalmente, em 1909, os irmãos resolveram mudar o nome do produto para Johnnie Walker. Era uma homenagem ao avô. Mas ambos tinham a preocupação em manter a tradição e a herança da marca, por isso o slogan: "Nascido em 1820, e ainda se fortalecendo" ("Born 1820, still going strong"). Nesse momento foi desenhado por Towne Brown, um popular cartunista da época, o mascote "Stridding Man", ou "O homem que caminhava com vigor, a passos largos e com determinação". No Brasil, ficou mais conhecido como "O Andarilho". Essa era a essência da imagem que o Johnnie Walker tentava transmitir. Curiosamente, o briefing foi passado ao desenhista num almoço, e o mascote, esboçado nas costas de um cardápio do restaurante. A tradicional figura com cartola de pele de castor, túnica vermelha, calça branca, botas de montaria e monóculo inquisidor representava com elegância o progresso, pioneirismo e a saga da família Walker. Nascia, assim, um dos primeiros e mais famosos mascotes da história do marketing.

Pouco depois, os irmãos deram novos nomes a seus uísques, em reconhecimento ao hábito de seus clientes de identificá-los pelos rótulos coloridos: assim surgiam oficialmente o Johnnie Walker Red Label e o Johnnie Walker Black Label (Anexo 2). E o resultado desses lançamentos não poderia ser melhor: Red Label tornou-se preferência mundial, uma distinção que se mantém até hoje. Desenvolvido para um mercado de exportação que busca drinques longos e refrescantes, é a marca que construiu o império Walker e definiu o negócio de uísques. Em 1920, já era possível encontrar as bebidas Johhnie Walker em 120 países ao redor do mundo. Naquela década, a tradicional garrafa quadrada se tornou padrão para todos os uísques da destilaria. Em 1934, a destilaria recebeu a primeira Concessão Real, um sinal de excelência, qualidade e reconhecimento, e tornou-se fornecedora da Casa Real Britânica.

\section{Andando para trás}

Em 1939, a família Walker saiu do negócio. Durante o século XX, a marca passou por vários donos. Ao final da Segunda Guerra, o produto transformou-se em símbolo de status, pois era a bebida preferida do estadista britânico Winston Churchill. As vendas subiram de um milhão de 
caixas, em 1945, para cinco milhões de caixas, em 1958. Na época, Johnnie Walker já era o uísque mais vendido do mundo. Nas décadas seguintes, a empresa resolveu investir no setor de distribuição para aumentar ainda mais a popularização da marca e seus uísques pelo mundo. Em 1986, a Johnnie Walker foi comprada pela cervejaria irlandesa Guinness, que em 1997 se fundiria com a Grand Metropolitan para formar a britânica Diageo.

Nesse mesmo ano de 1997, uma inesperada perda de market share estremeceu a história de ascensão do Johnnie Walker. O maior bem adquirido da Diageo respondia por $25 \%$ do lucro global da companhia, que estava abalada por um mercado de bebidas alcoólicas cada dia mais concorrido. $\mathrm{Na}$ década de 1990, o segmento de uísque foi perdendo espaço para outras bebidas, como vinho, champanhe, vodca e bebidas prontas, como a Smirnoff Ice. Os jovens enxergavam o uísque como "a bebida de seus pais". A ideia de que beber uísque trazia status tinha envelhecido junto com a história. Dessa forma, o ambiente externo estava desfavorável, e internamente também havia lacunas e oportunidades de melhoria.

Quando as campanhas de comunicação da Johnnie Walker eram comparadas às propagandas de outras marcas de uísque (Anexo 3), existia uma grande semelhança, não havia algo que a diferenciasse das demais nesse mercado competitivo, ou seja, a função da publicidade era sobretudo informativa. O produto ainda era líder, mas a marca, um dos principais legados da família Walker, estava fragilizada. Seguindo o próprio mercado de uísques, alguns anúncios da Johnnie Walker mantinham o foco totalmente no produto, característica marcantes da comunicação dessa indústria.

\section{Andando para a frente}

Foi nesse cenário de problemas que encontraram as oportunidades, e nasceu a campanha global "Keep walking", uma tentativa de resgatar os valores fundamentais de diferenciação da marca Johnnie Walker. O conceito Keep Walking surgiu em 1999. Peter Dee, uma equipe da Diageo e da agência de publicidade BBH tinham como desafio unificar e construir uma marca global única, pois a comunicação era descentralizada até então. Na época, mais de 30 diferentes campanhas anunciavam o produto em todo o mundo. O Brasil foi um dos quatro países líderes na criação da campanha, que partiu da ideia de que Johnnie Walker poderia inspirar o progresso pessoal. A equipe criativa conectou a história da marca, do Striding Man, com o reconhecimento de que todo homem quer progredir, resumido com maestria no insight "Keep walking" (Anexo 4).

Apesar de o tão conhecido símbolo da marca, Stridding Man ou Andarilho, ter sido redesenhado através dos anos por uma sucessão de grandes artistas plásticos, entre eles, Basil Partridge, Leo Cheney, Clive Upton e Michael Peters, as alterações foram pequenas. Sua roupa foi alterada ocasionalmente, tornando-se um dos símbolos publicitários mais reconhecidos no mundo e um verdadeiro ícone da indústria de bebidas alcoólicas. Todavia, foi a partir dessa campanha de marketing que, em 2000, o Andarilho ganhou uma importante reformulação visual, quando Johnnie Walker apresentou suas novas garrafas e rótulos. A principal diferença entre o desenho original e o novo foi a alteração no sentido da caminhada, acompanhando o sentido de leitura ocidental: da esquerda para a direita. Para reforçar a ideia do conceito "Keep walking", a direção foi invertida. Antes, ele andava para o lado esquerdo, visto do nosso ângulo (sentido contrário ao que escrevemos), o que, segundo os profissionais de marketing da Diageo, era contraproducente à proposta de progresso e conquistas, conforme Figura 1. 
Figura 1. Evolução visual do Andarilho

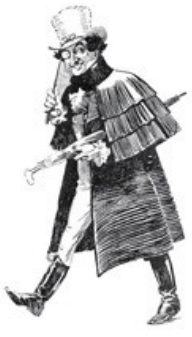

1909

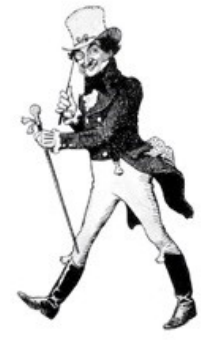

)

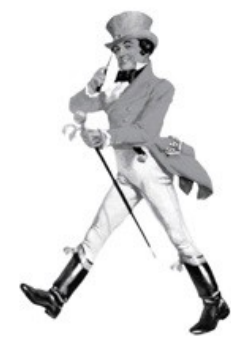

)

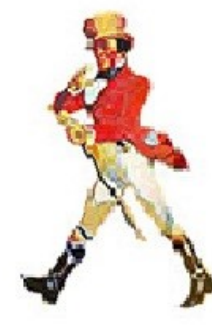

1925

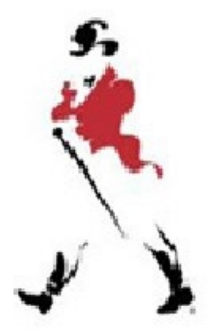

1996

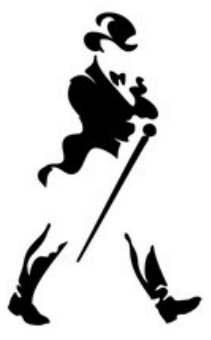

2000

Com essa junção da nova marca e do novo conceito do seu slogan (Keep walking) perante o mercado mundial, o uísque efetuou, então, sua primeira ação publicitária global, com custo inicial de US\$ 150 milhões. O conceito da campanha era simples, porém com valores muito fortes a serem associados à marca: "Continue andando", que representava o progresso humano, o "seguir em frente", a evolução e o pioneirismo, se fortalecendo assim o brand equity da Johnnie Walker. Hoje, a empresa parece explorar muito bem esse prestígio em suas extensões premiuns. Uma garrafa de Blue Label, o uísque top de linha da marca, custa, em média, $\mathrm{R} \$ 600,00$. Com esse resgate de valores tão intrínsecos, o sucesso voltou a caminhar lado a lado com a marca. Se compararmos, em 1999, foram vendidas 9 milhões de caixas de Johnnie Walker no mundo; já em 2007 esse número ultrapassou 15 milhões de caixas - 180 milhões de garrafas. Um crescimento plausível para um produto cujas vendas tinham aparentemente estagnado.

Uma nova fase da campanha surgia, trazendo o título "Eu não sou o futuro. Você é", que mostrava um robô que falava diretamente com o telespectador (Anexo 5). Ele se dizia mais forte, mais rápido e afirmava que, com certeza, duraria muito mais tempo. Apesar disso, falava que, se pudesse desejar algo, desejaria ser humano. O personagem afirma que, enquanto ele só precisa evitar desgastes para ser imortal, o homem tem que fazer algo notável para tornar-se eterno. É uma das campanhas publicitárias mais bem-sucedidas do mundo e foi veiculada em mais de 120 países.

Em 2008, a Johnnie Walker lançou mais uma campanha global para comemorar os 100 anos de criação de seu ícone. A história traçada pelo próprio John Walker, criador do produto, foi o ponto de partida para o comercial "Strides". Com direção de Rob Sanders e aproximadamente 150 pessoas envolvidas, o comercial foi filmado durante seis dias na Hungria e na Noruega, enquanto a edição e a finalização aconteceram em Nova Iorque e Londres. O filme, criado pela agência BBH de Londres, tem início com o fundador da empresa empurrando um barril de uísque, ação seguida por cenas que ilustram a evolução da humanidade nos últimos 100 anos, enaltecendo o posicionamento de continuar andando em frente e superando os desafios.

Após a marca estar bem-reposicionada globalmente, ocorreu uma situação inesperada: o produto desenvolveu uma campanha em 2011 específica para apenas uma nação. A Diageo decidiu utilizar o slogan "Keep walking" para passar uma mensagem ao Brasil, com o objetivo de ressaltar a importância do País para a marca. De acordo com Alexandre Gama, diretor-geral de criação da agência, o desafio foi lançado quando uma equipe internacional da Diageo, que é cliente da BBH desde 1999 e da Neogama desde 2004, se reuniu com a Neogama, em São Paulo. Os executivos mostraram a intenção de ter uma ação focada apenas no Brasil. "Eles estavam otimistas com o nosso país e gostariam de fazer algo que mostrasse a importância do Brasil para a Diageo e para o mundo", disse o executivo.

As cenas do filme mostram o morro do Pão de Açúcar, no Rio de Janeiro, sendo "acordado". Ele se levanta e, já em pé, segue em direção ao mar. O gigante desperta curiosidade e patriotismo nas pessoas que acompanham o seu processo de mutação. Ao final do comercial, a mensagem: "O gigante não está mais adormecido. Keep walking, Brazil" (Anexo 6). A inclusão do nome do País ao 
final do slogan também é um fato inédito na comunicação da marca. "O objetivo é mostrar que Johnnie Walker está mandando um recado direto para o País e acredita que ele deve continuar seguindo em frente", revela Gama. O diretor explica que a escolha de serviços especializados fora do País se deu por conta da necessidade de não perder a estética dos comerciais globais da marca. "Apesar de ser uma campanha brasileira, é um produto escocês. Não queremos abrasileirar o produto", explicou.

Se as vendas mundiais vão muito bem, no Brasil elas vão ainda melhor. O Brasil tornou-se o maior mercado consumidor do Johnnie Walker Red Label no mundo. Existe uma possível explicação para essa liderança brasileira que merece destaque. O fato é que o Johnnie Walker Red Label caiu no gosto do brasileiro, sobretudo do nordestino. É comum ver as pessoas tomando uísque com água de coco, na praia. "O Red é um uísque mais suave e mais fácil de beber. Ele combina muito bem com o clima tropical", diz Charles Maclean, jornalista escocês especializado em bebidas. "É difícil de acreditar, mas vendemos mais o 'rótulo vermelho' no Nordeste do que no Sudeste", afirma Eduardo Bendzius, diretor de marketing no Brasil da Diageo. Apesar de o Brasil ser um dos principais consumidores de uísque no mundo, com a capital pernambucana apresentando o maior consumo per capita do produto, um dos desafios que Johnnie Walker encontrou no Brasil foi a falta de um conceito de mistura de bebidas. Por isso, passou a promover o mix de Johnnie Walker em festas com a presença de um bartender. Para aguçar a curiosidade e atrair a atenção dos presentes, as misturas eram servidas apenas em copos vermelhos.

A evolução da marca continuou durante os anos com algumas alterações, não só no Andarilho, mas o nome Johnnie Walker passou a ser posicionado abaixo do ícone e para reforçar a ideia do conceito "Keep walking". Depois, a identidade visual adotou uma nova tipografia, excluindo o tipo manuscrito para usar um sem serifa, deixando-o mais sério e atual. O logotipo também passou a ser aplicado, além de na tradicional cor preta, em cores mais estimulantes, dependendo da situação, como amarelo, que simboliza felicidade, ou dourado, que simboliza a realeza no Ocidente. Posteriormente, a marca adotou um novo tipo de letra: serifada. Os tipos com serifa carregam uma ideia mais clássica, e nesse caso adicionou-se um toque de sofisticação, conforme Figura 2.

\section{Figura 2. Evolução da tipografia da marca}

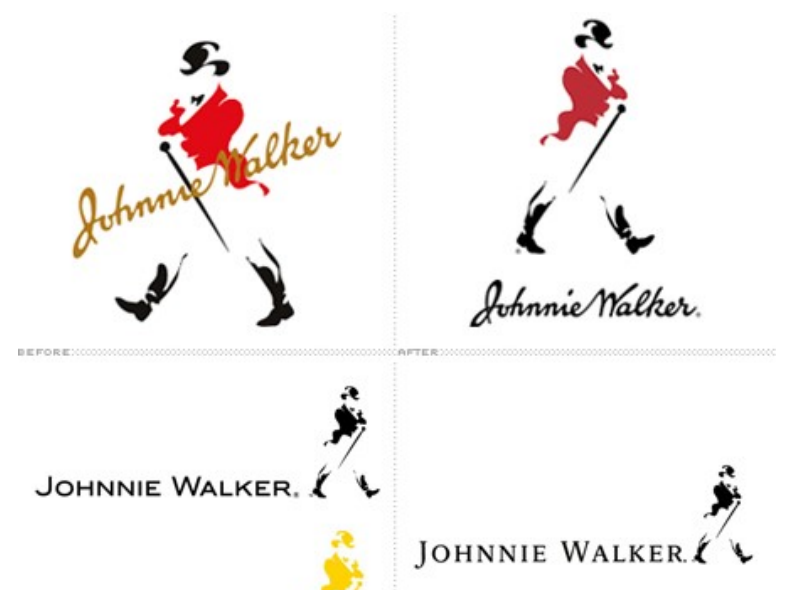

Em fevereiro de 2015, a Johnnie Walker introduziu mais uma mudança no seu símbolo, desenhado em colaboração com o ilustrador Garry Redford (Anexo 7). Segundo ele, o estilo 
atemporal é o ajuste perfeito para a marca. Nessa mais nova atualização, o Andarilho ficou menos abstrato e passou a ter mais detalhes, como nos braços, no rosto, e não segura mais o monóculo, agora está tocando o chapéu, conforme Figura 3.

\section{Figura 3. Comparação da versão anterior com a nova ilustração do Andarilho}

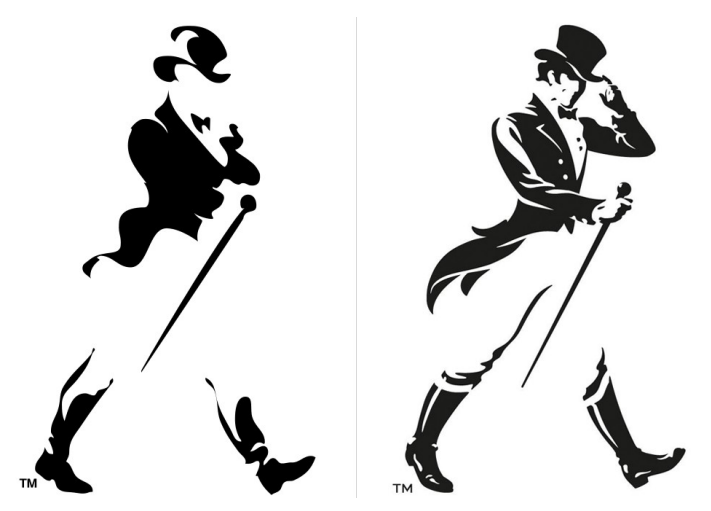

A embalagem dos uísques Johnnie Walker é um dos componentes mais importantes da marca, porém um produto com mais de 150 anos não poderia manter-se sem modificações por tanto tempo, e, para solucionar esse problema, a marca está sempre lançando embalagens promocionais. Além dos modelos tradicionais, apostou em produtos premium, criando linhas posicionadas como opções de presentes em packs acompanhando brindes como taças. Muitos desses produtos eram exibidos em displays e até em vitrinas luxuosas, onde o cliente podia entrar para degustar.

O investimento no sentimento de progressão pessoal não estava presente só em sua comunicação publicitária, se mostrava também por meio de ações como o patrocínio à equipe de Fórmula 1 McLaren Mercedes, ou na ação de comemoração aos 100 anos do Striding man que convidou consumidores VIPs em Recife, no ano de 2008, a fazer um passeio de helicóptero enquanto conheciam brevemente a biografia de personalidades pernambucanas de sucesso marcadas pelo progresso pessoal, como o cantor Alceu Valença, o engenheiro e cientista Silvio Meira, o jogador de vôlei Pampa e o chefe de cozinha César Santos. Durante entrevista no evento, o diretor de marketing da Diageo Marcello Ursini enfatizou que "viver o que a marca significa é passar por experiências como essa". Ter experiência com a marca é visto como essencial para a brand manager Eliza Duque Estrada. "Uma das ações da empresa foi um ônibus itinerante. Os consumidores podiam entrar e experimentar o produto em um ambiente de festa", ressalta.

Em 2005, foi criado o programa Keep Walking Club, com o objetivo de estabelecer um processo de relacionamento com os consumidores, aumentando a lealdade com a marca e sua frequência de consumo. Hoje, a marca também é vista em muitos brindes diferenciados, como camiseta e outros itens de moda. O Andarilho foi utilizado de maneira muito discreta em camisas. "A intenção não é entrar no mercado de moda ou trabalhar com brindes de modo genérico, a diversidade de brindes vem da necessidade de atender vários consumidores", explica Eliza.

\section{Caminhando para o futuro}

Para os próximos anos, a Diageo possui uma meta mundial grandiosa: quadruplicar suas vendas. Os planos ambiciosos de expansão chegam num momento em que a empresa já está crescendo (muito, quando comparada às concorrentes). Em 2015, as vendas mundiais cresceram $9,5 \%$, praticamente cinco vezes mais do que as outras marcas. Para especialistas do setor, crescer 
rapidamente, como deseja a gigante de destilados, exige a entrada na China, Rússia e Índia, e altos investimentos em marketing e publicidade.

A aposta, agora, é o conceito do "drink as you wish", ou "beba como quiser", onde as pessoas criam seus próprios drinques à base de uísque. "As pessoas têm de ter liberdade para beber como preferirem", diz o diretor Eduardo Bendzius. No mercado de uísques, a principal estratégia da empresa é a de promover seu consumo misturado com outras bebidas, porém esse mercado ainda não está pronto para a categoria de uísque no Brasil, apesar de, no Nordeste, já ser comum beber com água de coco. O desafio da empresa é seduzir os consumidores das baladas das grandes capitais do mundo a fazerem o mesmo.

Vender mais é indiscutivelmente uma meta para a empresa, porém ela é ciente de que seu maior desafio como uma indústria de bebidas alcoólicas é a responsabilidade de consumo. Quando questionada sobre o tema acima, a Diageo diz que direciona $20 \%$ de sua verba de marketing para ações de conscientização, como o movimento Piloto da Vez, uma tentativa de conscientizar os jovens a ir para a balada com um motorista que não beba. Então, além de tentar rejuvenescer o consumo, deve atrelar sua história inspiradora de progresso e superação ao consumo consciente e responsável dos jovens.

Assim como a indústria de cigarros, a de bebidas alcoólicas precisa pensar e repensar seu posicionamento e a identidade da marca. Há um paradoxo no qual o aumento de vendas do produto pode representar um impacto social.

No Dia Internacional da Mulher, em 2018, a empresa lançou uma edição limitada, em que o mascote Johnnie Walker foi substituído pela Jane Walker (Anexo 8), com a finalidade de promover a igualdade de gênero. O lançamento da Jane Walker faz parte da mais recente campanha da marca, "Keep walking America", que começou em 2016 e tenta atingir um público mais amplo, com anúncios que trazem figuras variadas. 
JOHNNIE WALKER: SEMPRE EM FRENTE

Levy Henrique Barbosa dos Santos, Beatriz Gondim Matos

Anexo 1. Um dos primeiros anúncios feitos em 1906, ainda contendo os três rótulos
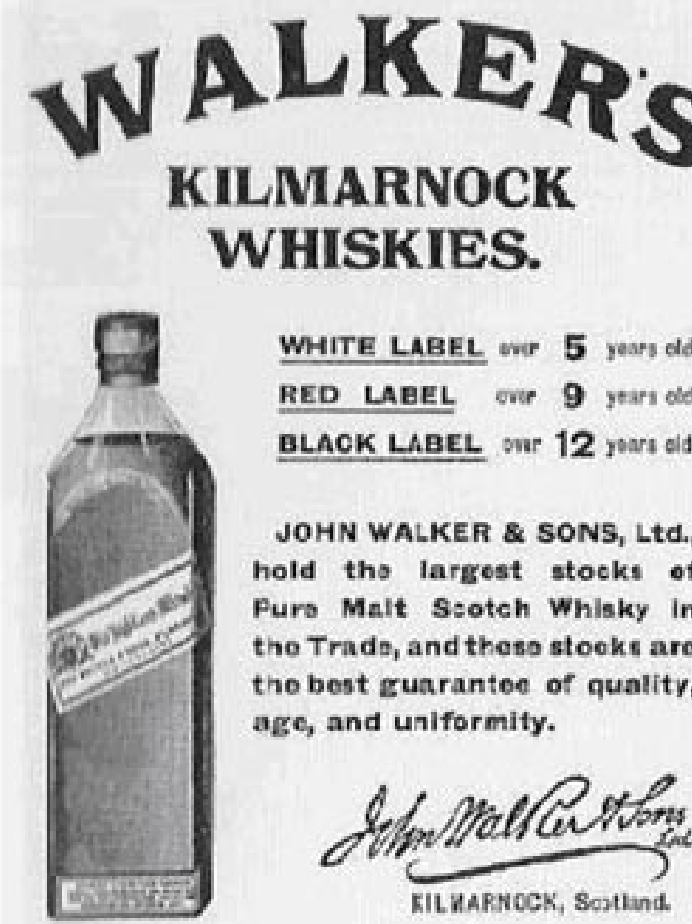

WHITE LABEL wor $\mathbf{5}$ years did.

RED LABEL eve 9 ytars eld.

BLACK LABEL owr 12 yours eld.

JOHN WALKER \& SONS, Ltd., hold the largest stocks of Purs Malt Ssotch Whisky in the Trads, and theso stooks are the best guarantee of quality, age, and uniformity.

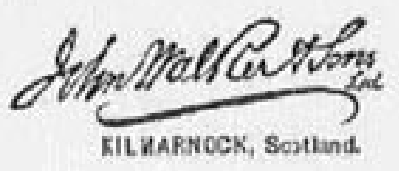

OBIAIMABLE EVERYWHEAE FROM ALL LICEHSED DEALER3.

Anexo 2. O Johnnie Walker Red Label e o Johnnie Walker Black Label

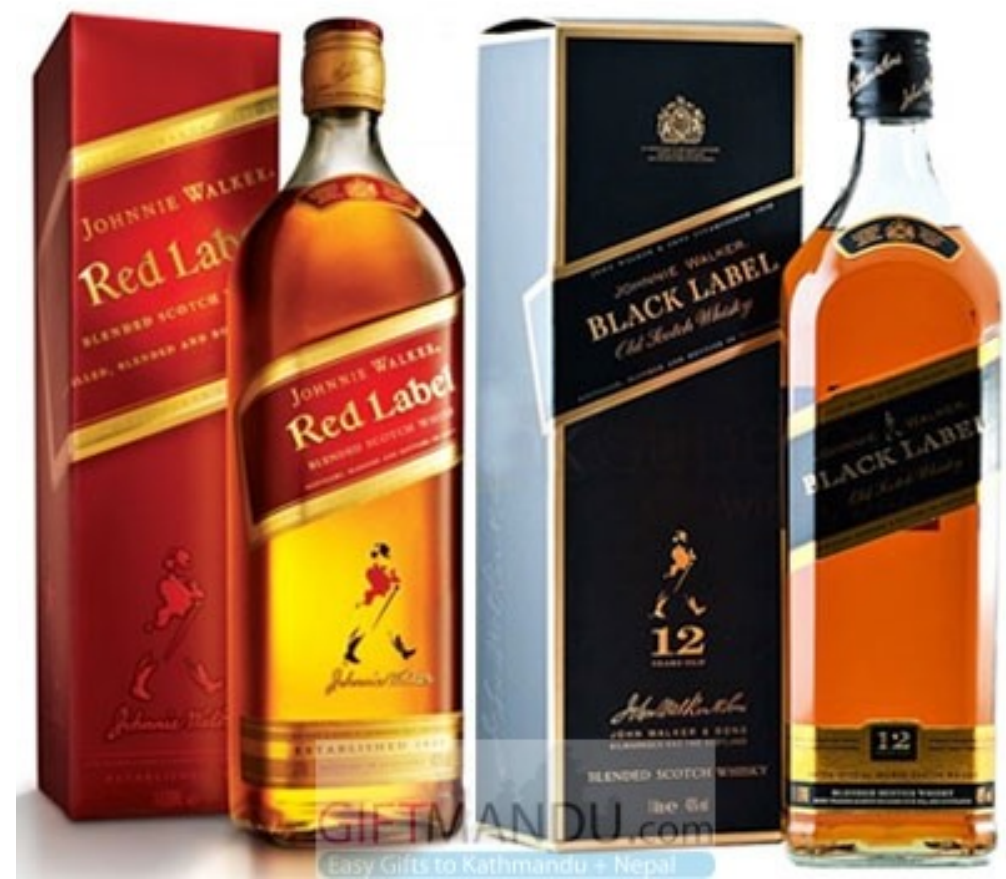


JOHNNIE WALKER: SEMPRE EM FRENTE

Levy Henrique Barbosa dos Santos, Beatriz Gondim Matos

Anexo 3. Comparação da comunicação da Johnnie Walker antes do reposicionamento com outras marcas
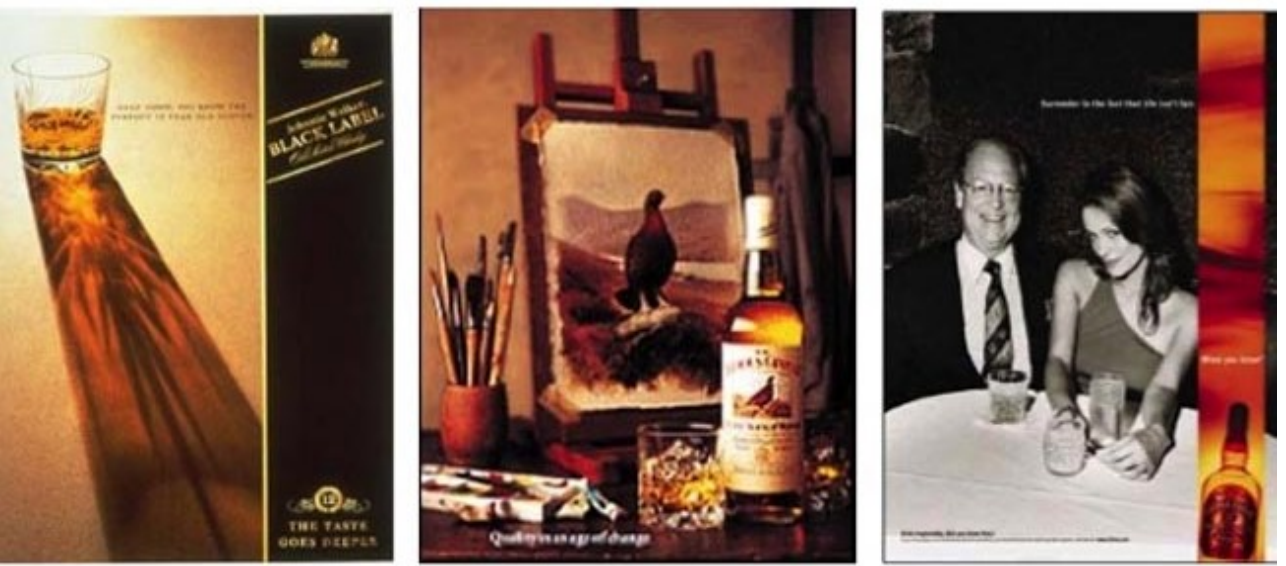

Anexo 4. Exemplos de algumas peças a partir da campanha global "Keep walking"
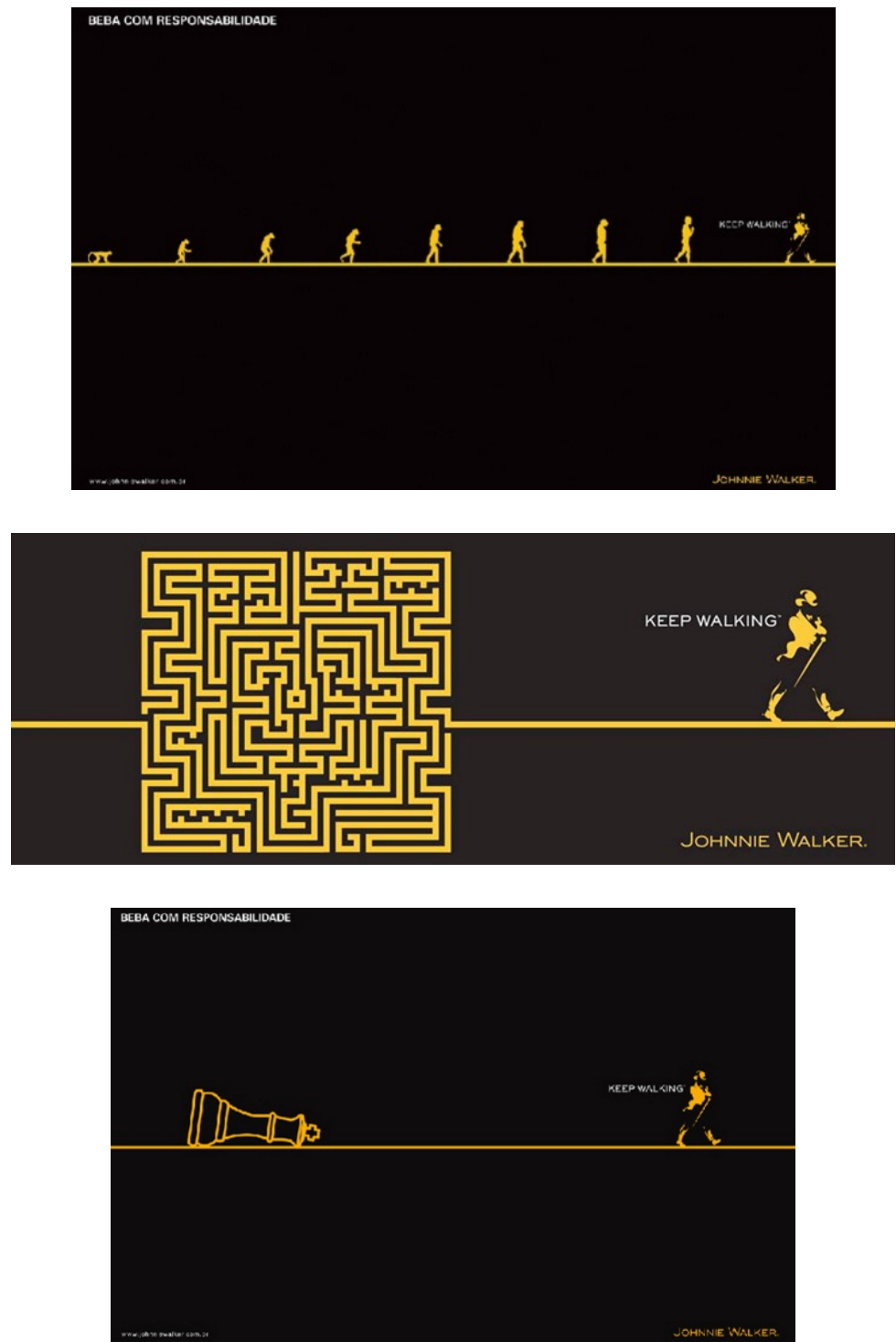
JOHNNIE WALKER: SEMPRE EM FRENTE

Levy Henrique Barbosa dos Santos, Beatriz Gondim Matos

Anexo 5. Peça da campanha "Eu não sou o futuro. Você é"

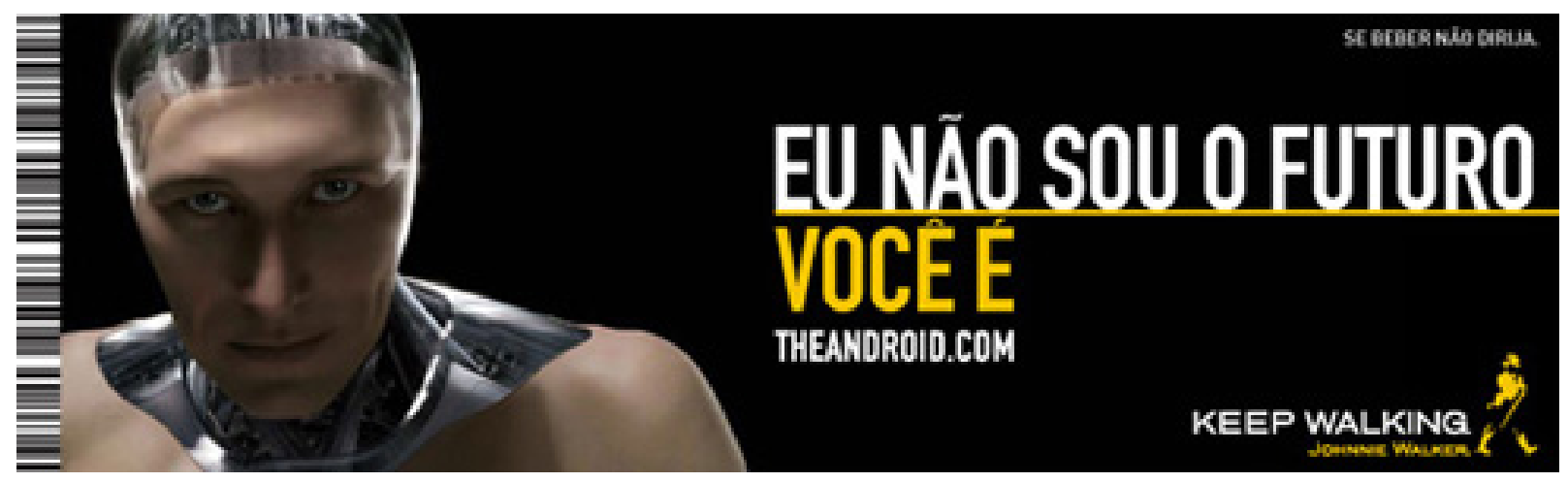

Anexo 6. Campanha focada numa única nação: "Keep walking, Brazill"

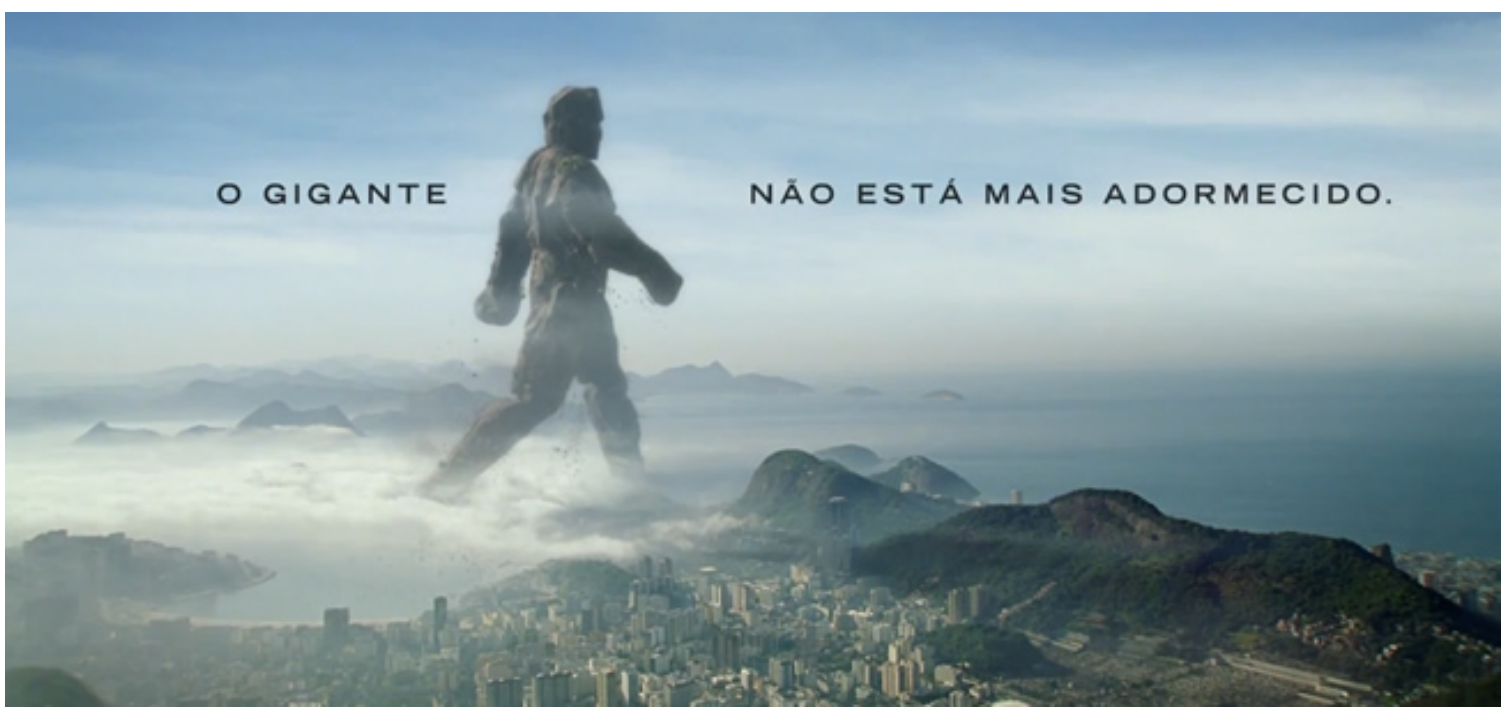


Anexo 7. Atual marca do Johnnie Walker, atualizada em 2015

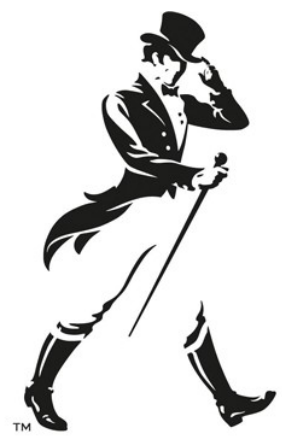

\section{JOHNNIE WALKER。 KE E W A L K I N G。}

Anexo 8. Jane Walker - Versão feminina do Johnnie Walker lançada em 2018
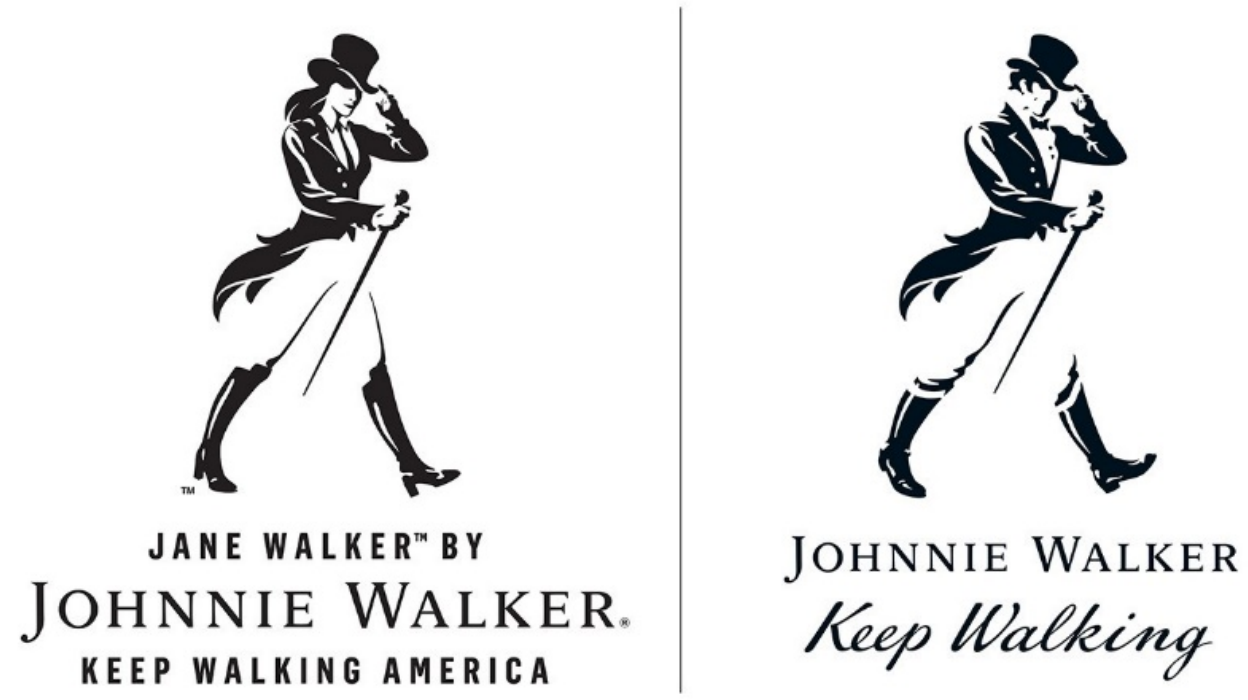